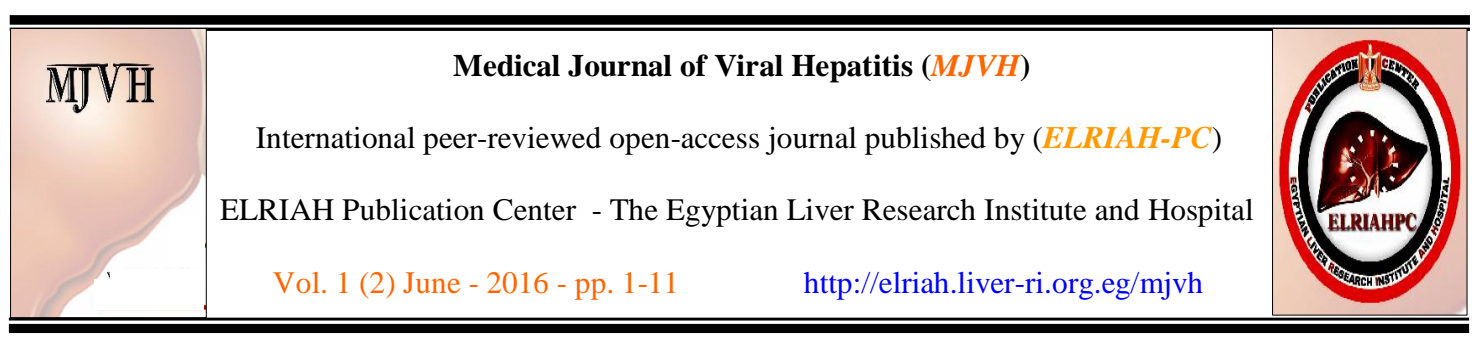

Original article

\title{
Interferon- $\lambda$ rs12979860CC genotype predicts sustained virological response to therapy in patients with chronic hepatitis C Genotype 4 but enhances hepatic fibrosis
}

\author{
Shiha, G. ${ }^{1,2 *}$, Samir, W. ${ }^{2,3}$, Seif, S. ${ }^{1,2}$, Soliman, R. ${ }^{2}$, Zalata, K. ${ }^{4}$, Helmy, A. ${ }^{2,5}$ \\ ${ }^{1}$ Internal Medicine dept., Faculty of Medicine, Mansoura Univ., Egypt. \\ ${ }^{2}$ Egyptian Liver Research Institute and Hospital (ELRIAH), Mansoura, Egypt. \\ ${ }^{3}$ Biochemistry dept., Faculty of Medicine, Mansoura Univ., Mansoura, Egypt \\ ${ }^{4}$ Cairo, Pathology dept., Faculty of Medicine, Mansoura Univ., Egypt. \\ ${ }^{5}$ Tropical Medicine \& Gastroenterology, dept., Faculty of Medicine, Assiut Univ., Assiut, Egypt. \\ *E-mail: g_shiha@hotmail.com
}

\section{Article History}

Received: 11/4/2016

Revised: $22 / 7 / 2016$

Accepted: 25/8/2016

Keywords:

Chronic hepatitis C

Genotype 4

Interleukin-28B

Hepatic fibrosis

Genetics

\begin{abstract}
:
Recently, several genome wide association studies (GWAS) have revealed that several single nucleotide polymorphisms (SNPs) in proximity to the interleukin (IL)-28B genes can predict spontaneous clearance of hepatitis $C$ virus (HCV) infection as well as sustained virological response (SVR) to Pegylated interferon- $\alpha 2 a / b$ plus ribavirin therapy. In $H C V$-genotype 1 patients, the allele rs 12979860 is associated with greater hepatic necro-inflammation and worse clinical outcome, but lower fibrosis progression. Data on patients infected with HCV genotype 4 (G4) is limited. The present study assesses the impact of rs 12979860 IL28 SNP on hepatic fibrosis and SVR in patients with chronic HCV G4 infection. A total of 163 patients with chronic HCV G4 infection (123 males and 40 females) who had pre-treatment liver biopsy were included. Both HCV RNA and IL28 rs12979860 genotypes were determined by real time polymerase chain reaction. Hepatic fibrosis, IL28B rs 12979860 genotype, and SVR were statistically correlated together and with various clinical, biochemical, and virological parameters. All patients were found to be infected with HCV G4. IL28B rs 12979860 genotypes TT, CT, and CC were detected in 29 (17.8\%), 107 (56.6\%), and 27 (16.6\%) patients, respectively. SVR was achieved in 85 (52.1\%), severe fibrosis ( $\geq F 3)$ by METAVIR score was found in 75 (64.0\%). The CC allele is associated with nearly twice $(O R=1.898)$ the risk for having severe fibrosis $(\geq F 3)$, but nearly 16 times $S V R$ $(O R=15.833)$ than having CT and TT. Contrary to HCV G1, the CC allele at IL28B rs12979860 appears to be associated with higher hepatic fibrosis, but better SVR to therapy in patients with chronic HCV G4 infection.
\end{abstract}

Abbreviations: $C H C$; chronic hepatitis C. GWAS; genome wide association studies. HCV; hepatitis C virus. IL-28B; interleukin-28B. Peg-IFN- $\alpha 2$; pegylated interferonalpha2. SNPs; single nucleotide polymorphisms. SVR; sustained viral response. G4; genotype 4. 


\section{Introduction}

Chronic hepatitis C virus (HCV) infection represents a serious public health problem, with an estimated worldwide prevalence of $3 \%$ [1]. HCV genotypes 1, 2 and 3 are common throughout America and Europe while genotype-4 (G4)is predominant in the Middle East and Africa, where it is responsible for more than $80 \%$ of $\mathrm{HCV}$ infections [1,2]. In Egypt, the prevalence of $\mathrm{HCV}$ is estimated to range from $14.7-22 \%$ with a predominance of G4 (90\%) followed by genotype $1[2,3]$. Host genetics controlling the immune-inflammatory pathways affects hepatic fibrosis [4-6]. Indeed, many studies reported that single nucleotide polymorphism (SNP) in proximity to interlukin-28B (IL28B) interferon- $\lambda($ IFN- $\lambda$ ) region (rs 12979860) is a predictor of sustained virological response (SVR) to IFN-based therapy [7-11].Several reports have showed that the rs 12979860 'CC'genotype is associated with greater inflammation grade [12-14]. The relation of rs12979860 'CC' genotype to hepatic fibrosis progression, however, is controversial [12-21]. The present study involved only chronic hepatitis C (CHC)G4 patients treated in a single center and aimed to clarify the impact ofrs 12979860 gene polymorphisms on hepatic fibrosis; to explore the interactions of rs12979860 genotype with host and viral factors; and to explore the impact of rs12979860 genotype on SVR to antiviral therapy in the same group of patients.

\section{Patients and Methods}

\subsection{Patients}

A total of 163 patients with chronic HCV-infection attending the Egyptian Liver Research Institute and Hospital
(ELRIAH), Mansoura, Egypt were included in this study.

\subsection{Approvals}

The study protocol conformed to the 1975 Declaration of Helsinki and was approved by the Institutional Review Board Research Ethics Committee in the hospital. All patients gave an informed consent prior to enrolment in the study and signed another informed consent prior to undergoing liver biopsies.

\subsection{Methods}

2.3.1. Baseline Assessment

Baseline (pre-treatment) clinical, hematological, biochemical, and serological data of all included patients were collected. Percutaneous liver biopsies were obtained according to standard protocols and were interpreted according to the METAVIR Score [22], by a single pathologist who was blinded to all other clinical, virological, molecular, and therapeutic data of the patients.

2.3.2. Therapy and Follow up

All patients were treated either with Peg-IFN $\alpha-2 a$ at doses of $180 \mu$ g subcutaneously once weekly respectively in combination with ribavirin $1000 \mathrm{mg}$ (body weight $\leq 75 \mathrm{~kg}$ ) or $1200 \mathrm{mg}$ (body weight $\geq$ $75 \mathrm{~kg}$ ). The complete course of therapy was 48 weeks. Patients were then followed up for another 24 weeks to assess for the development of SVR.

\subsection{Definitions}

The SVR was defined as undetectable HCV RNA 24 weeks after end of treatment (i.e., at week 72). Nonresponse was designated when HCV RNA did not drop >2 $\log 10$ from the pretreatment values at 12 weeks of treatment. 
Relapse was designated when HCV RNA reappeared within 24 weeks after end of treatment response. Both non-responders and relapsers were grouped as "No-SVR" group in this study.

\subsection{Detection of HCV RNA and HCV genotyping}

HCV RNA was detected by real time PCR using AmpliprebTaqMan, Roche Diagnostics. HCV RNA genotypes were determined by Real Time PCR (Light Cycler 480, Roche diagnostics).

\subsection{IL-28B genotyping}

IL28 B polymorphism was determined by Real Time PCR (Slan Real Time PCR detection system, LG Life Sciences, Korea) using Amplisense, Genoscreen-IL28 B FRT PRC kit (Amplisense, Moscow, Russia). Discrimination between wild type and mutant allele was achieved based on labeling the probes with two different dyes namely VIC for wild type of FAM for mutant allele.

\subsection{Statistical Analyses}

Data were collected initially in a specialized data collection form, then introduced into a Microsoft Excel worksheet, and finally transferred to the Statistical Package for Social Sciences (SPSS) version 16.0 for Windows (SPSS 16.0, SPSS Inc., Chicago, IL, USA) for analyses. A P value of $<0.05$ was considered statistically significant.
Means of continuous variables were compared using Student's $t$-tests or nonparametric tests (Wilcoxon's and Mann Whitney), as appropriate. The Chi-Square or Fisher's exact tests were used to compare frequencies and proportions. Multivariate stepwise logistic regression analysis was performed to determine the role of genetic and bio-clinical characteristics as independent predictors of SVR and advanced hepatic fibrosis. Only variables, that were found to be significant at the 0.05 level at univariate analyses were included in multivariate logistic regression analysis.

\section{Results}

\subsection{Patients' characteristics}

The study comprises 163 patients with $\mathrm{CHC}$, studied and treated in a single center. The mean age was $45.2,75.5 \%$ were males, $90.2 \%$ had body mass index (BMI) of $\geq 25 \mathrm{Kg} / \mathrm{m}^{2}$, and none had any history of alcohol intake. The rs allele distribution was CC, CT, and TT in $16.6 \%$, $65.5 \%$, and $17.8 \%$ of patients, respectively. Regarding pathology, severe fibrosis (METAVIR $\mathrm{F} \geq 3$ ) and severe inflammation (METAVIR $\mathrm{A} \geq 3$ )were found in $64.0 \%$ and $90.2 \%$ of patients, respectively. SVR was achieved in $85(52.1 \%)$ patients. Detailed baseline demographic, laboratory, and histologic data of the whole cohort are shown in table (1).

Table (1) Characteristics of all chronic HCV-G4 patients and according to hepatic fibrosis and response to therapy

\begin{tabular}{|c|c|c|c|c|c|c|c|}
\hline \multirow[b]{2}{*}{ Variable } & \multirow{2}{*}{$\begin{array}{c}\text { All } \\
(n=163)\end{array}$} & \multicolumn{3}{|c|}{ Hepatic Fibrosis } & \multicolumn{3}{|c|}{ Response to Therapy } \\
\hline & & $\begin{array}{c}F 0-2 \\
(n=99)\end{array}$ & $\begin{array}{c}F 3-4 \\
(n=79)\end{array}$ & P value & $S V R(n=86)$ & $\begin{array}{c}\text { No SVR } \\
(n=78)\end{array}$ & $\begin{array}{c}P \\
\text { value }\end{array}$ \\
\hline Age (Years) & $45.2 \pm 8.2$ & $43.3 \pm 8.1$ & $47.3 \pm 7.8$ & 0.002 & $46.0 \pm 8.5$ & $44.3 \pm 7.9$ & 0.124 \\
\hline \multicolumn{8}{|l|}{ Age group } \\
\hline - $\quad<40$ years & $38(23.3)$ & $26(29.5)$ & $12(16.0)$ & 0.041 & $17(20.0)$ & $21(26.9)$ & 0.296 \\
\hline$\geq 40$ years & 125 (76.7) & $62(70.5)$ & $63(84.0)$ & & $68(80.0)$ & $57(73.1)$ & \\
\hline
\end{tabular}




\begin{tabular}{|c|c|c|c|c|c|c|c|c|}
\hline \multicolumn{9}{|c|}{ Gender } \\
\hline- & Male & $123(75.5)$ & $65(73.9)$ & $58(73.3)$ & \multirow[t]{2}{*}{0.608} & $66(77.6)$ & $57(73.1)$ & \multirow[t]{2}{*}{0.498} \\
\hline- & Female & $40(24.5)$ & $33(26.1)$ & $17(22.7)$ & & $19(22.4)$ & $21(26.9)$ & \\
\hline \multicolumn{2}{|c|}{ BMI $\left(\mathrm{Kg} / \mathbf{m}^{2}\right)$} & $30.3 \pm 3.9$ & $29.7 \pm 3.8$ & $31.2 \pm 4.0$ & 0.016 & $30.3 \pm 0.4$ & $30.4 \pm 3.9$ & 0.900 \\
\hline \multicolumn{9}{|c|}{ BMI group } \\
\hline & $<25 \mathrm{Kg} / \mathrm{m}^{2}$ & $16(9.8)$ & $10(11.4)$ & $6(8.0)$ & \multirow[t]{2}{*}{0.472} & $10(11.8)$ & $6(7.7)$ & \multirow[t]{2}{*}{0.383} \\
\hline & $\geq 25 \mathrm{Kg} / \mathrm{m}^{2}$ & $147(90.2)$ & 78 (88.6) & $69(92.0)$ & & $75(88.2)$ & $72(92.3)$ & \\
\hline \multicolumn{2}{|c|}{ ALT (IU/mL) } & $73.0 \pm 59.9$ & $51.3 \pm 29.4$ & $98.5 \pm 75.0$ & 0.000 & $73.0 \pm 58.5$ & $73.1 \pm 61.8$ & 0.742 \\
\hline \multicolumn{2}{|c|}{ AST (IU/mL) } & $60.0 \pm 43.8$ & $39.3 \pm 19.7$ & $84.2 \pm 51.5$ & 0.000 & $60.7 \pm 44.6$ & $59.2 \pm 43.3$ & 0.734 \\
\hline \multicolumn{2}{|c|}{$\operatorname{Albumin}(\mathrm{g} / \mathrm{L})$} & $4.3 \pm 0.3$ & $4.4 \pm 0.3$ & $4.2 \pm 0.4$ & 0.016 & $4.3 \pm 0.3$ & $4.4 \pm 0.3$ & 0.063 \\
\hline \multicolumn{2}{|c|}{ Bilirubin (mg/L) } & $0.9 \pm 0.2$ & $0.9 \pm 0.2$ & $0.9 \pm 0.2$ & 0.546 & $0.9 \pm 0.2$ & $0.9 \pm 0.2$ & 0.881 \\
\hline \multicolumn{2}{|c|}{$\operatorname{ALP}(\mathbf{I U} / \mathbf{m L})$} & $82.6 \pm 17.8$ & $76.9 \pm 15.5$ & $89.27 \pm 18.2$ & 0.000 & $82.1 \pm 19.8$ & $83.1 \pm 15.5$ & 0.769 \\
\hline \multicolumn{2}{|c|}{ HCV RNA (copies/ml) } & $58 \mathrm{E} 5 \pm 32 \mathrm{E} 4$ & $67 \mathrm{E} 5 \pm$ & $\begin{array}{c}5.8 \mathrm{E} 5 \pm 5.0 \\
\mathrm{E} 5\end{array}$ & 0.447 & $5.5 \mathrm{E} 5 \pm 6.2 \mathrm{E} 5$ & $6.2 \mathrm{E} 5 \pm 8.3 \mathrm{E} 5$ & 0.504 \\
\hline \multicolumn{2}{|c|}{ HCV RNA $\left(\log _{10}\right)$} & $5.5 \pm 0.6$ & $5.5 \pm$ & $5.4 \pm 0.5$ & 0.447 & $5.4 \pm 0.6$ & $5.5 \pm 0.5$ & 0.504 \\
\hline \multicolumn{9}{|c|}{ HCV group } \\
\hline & $<400,000 / \mathrm{ml}$ & $97(59.5)$ & $48(54.5)$ & $49(65.3)$ & \multirow[t]{2}{*}{0.162} & $48(56.5)$ & $49(62.8)$ & \multirow[t]{2}{*}{0.40} \\
\hline & $\geq 400,000 / \mathrm{ml}$ & $66(40.5)$ & $40(45.5)$ & $26(34.7)$ & & $37(43.5)$ & $29(37.2)$ & \\
\hline \multicolumn{9}{|c|}{ HCV group } \\
\hline & $<600,000 / \mathrm{ml}$ & $106(65.0)$ & $54(61.4)$ & $52(69.3)$ & \multirow[t]{2}{*}{0.288} & $54(63.5)$ & $52(66.7)$ & \multirow[t]{2}{*}{0.67} \\
\hline & $\geq 600,000 / \mathrm{ml}$ & $57(35.0)$ & $34(38.6)$ & $23(30.7)$ & & $31(36.5)$ & $62(33.3)$ & \\
\hline \multicolumn{9}{|c|}{ Grade* } \\
\hline- & 0.2 & $16(9.8)$ & $80(90.9)$ & $15(20.0)$ & \multirow[t]{2}{*}{0.000} & $52(61.2)$ & $43(55.1)$ & \multirow[t]{2}{*}{0.43} \\
\hline- & $3-4$ & $147(90.2)$ & $8(9.2)$ & $60(80.0)$ & & $33(38.8)$ & $35(44.9)$ & \\
\hline \multicolumn{9}{|c|}{ Stage* } \\
\hline- & 0.2 & $88(54.0)$ & \multirow[t]{2}{*}{ - } & - & \multirow[t]{2}{*}{-} & $44(51.8)$ & $44(56.4)$ & 0.552 \\
\hline- & $3-4$ & $75(46.0)$ & & - & & $41(48.2)$ & $34(43.6)$ & \\
\hline IL28B & NPs & & & & & & & \\
\hline rs1297 & 360 & & & & & & & \\
\hline- & $\mathrm{CC}$ & 27 (16.6) & $11(12.5)$ & $16(21.3)$ & 0.314 & 25 (29.4) & $2(2.6)$ & 0.000 \\
\hline- & $\mathrm{CT}$ & $107(65.6)$ & $61(69.3)$ & $46(61.3)$ & & $53(62.4)$ & $54(69.2)$ & \\
\hline- & TT & $29(17.8)$ & $16(18.2)$ & $13(17.3)$ & & $7(8.2)$ & $22(28.2)$ & \\
\hline $\begin{array}{l}\text { IL28B } \\
\text { rs1297 }\end{array}$ & $\begin{array}{l}\text { NPs } \\
\mathbf{3 6 0}\end{array}$ & & & & & & & \\
\hline $\begin{aligned} 151291 \\
-\end{aligned}$ & $\mathrm{CC}$ & $27(16.6)$ & $11(12.5)$ & $16(21.3)$ & 0.131 & 25 (29.4) & $2(2.6)$ & 0.001 \\
\hline- & Non-CC & $136(83.4)$ & 77 (87.5) & $59(78.7)$ & & $60(70.6)$ & $76(97.4)$ & \\
\hline IL28B & NPs & & & & & & & \\
\hline rs1297 & & & & & 0.888 & & & 0.001 \\
\hline- & TT & $134(82.2)$ & $16(18.2)$ & $13(17.3)$ & & $7(8.2)$ & $22(28.2)$ & \\
\hline- & Non-TT & $29(17.8)$ & $72(81.8)$ & $62(82.7)$ & & $78(91.8)$ & $56(71.8)$ & \\
\hline
\end{tabular}

Data expressed as mean $\pm S D$ or $n$ (\%) as appropriate. $n$; number. $H C V$; hepatitis $C$ virus.

BMI; body mass index. SVR; sustained viral response. SNPs; single nucleotide polymorphisms. *Grade (of inflammation) and *Stage (of fibrosis) by METAVIR score. ALT; alanine transaminase. AST; Aspartate transaminase. ALP; alkaline phosphatase.

3.2. Characteristics of the patients' rs12979860 genotypes

Detailed baseline demographic, laboratory, and histologic data of patients with "CC" genotype versus those with "CT/TT genotype are shown in table (2). and figure (1-a \& b). Compared to patients with rs129798660 genotypes CT/TT, patients with the genotype $\mathrm{CC}$ were associated with nearly twice severe fibrosis $(\mathrm{P}=0.131$; OR: 1.9$)$ and more SVR $(\mathrm{P}=$ 0.001; OR: 15.8). SVR was achieved in $25(92.6 \%)$ of the 27 patients who have the "CC" allele of the rs12979860 gene, and in only $60(44.1 \%)$ of the 136 patients who have "CT/TT" genotypes $\left(\mathrm{P}=0.001\right.$; tab $_{\mathrm{s}}$. (2\&3). 
Table (2) Comparison between patients infected with HCV genotype 4 without or with the "CC" allele

\begin{tabular}{|c|c|c|c|c|}
\hline Variable & $\begin{array}{c}C T / T T \\
(n=136)\end{array}$ & $\begin{array}{c}C C \\
(n=27)\end{array}$ & P value & OR $(95 \% C I)$ \\
\hline Age (Years) & $44.5 \pm 8.3$ & $47.7 \pm 6.9$ & 0.016 & - \\
\hline \multicolumn{5}{|l|}{ Age group } \\
\hline - <40 years & $35(25.7)$ & $3(11.1)$ & 0.101 & $2.77(0.79-9.78)$ \\
\hline - $\quad \geq 40$ years & $101(74.3)$ & $24(88.9)$ & & \\
\hline \multicolumn{5}{|l|}{ Gender } \\
\hline Male & $101(74.3)$ & $22(81.5)$ & 0.426 & $1.53(0.54-4.33)$ \\
\hline Female & $35(25.7)$ & $5(18.5)$ & & \\
\hline BMI $\left(\mathrm{Kg} / \mathbf{m}^{2}\right)$ & $30.4 \pm 3.9$ & $30.1 \pm 4.8$ & 0.964 & - \\
\hline \multicolumn{5}{|l|}{ BMI group } \\
\hline$-\quad<25 \mathrm{Kg} / \mathrm{m}^{2}$ & $12(8.8)$ & $4(14.8)$ & 0.339 & $0.56(1.17-1.88)$ \\
\hline$-\quad \geq 25 \mathrm{Kg} / \mathrm{m}^{2}$ & $124(91.2)$ & $23(85.2)$ & & \\
\hline ALT (IU/mL) & $74.5 \pm 63.4$ & $65.5 \pm 37.5$ & 0.899 & - \\
\hline AST (IU/mL) & $60.8 \pm 44.5$ & $56.0 \pm 34.8$ & 0.842 & - \\
\hline Albumin $(g / L)$ & $4.3 \pm 0.3$ & $4.2 \pm 0.4$ & 0.063 & - \\
\hline Bilirubin (mg/L) & $0.92 \pm 0.16$ & $0.85 \pm 0.15$ & 0.015 & - \\
\hline $\operatorname{ALP}(\mathbf{I U} / \mathbf{m L})$ & $83.7 \pm 16.9$ & $76.9 \pm 21.3$ & 0.096 & - \\
\hline HCV RNA (copies/ml) & $5.8 \mathrm{E} 4 \pm 7.7 \mathrm{E} 5$ & $6.0 \mathrm{E} 5 \pm 5.2 \mathrm{E} 5$ & 0.234 & - \\
\hline HCV RNA $\left(\log _{10}\right)$ & $5.4 \pm 0.5$ & $5.5 \pm 0.5$ & 0.234 & - \\
\hline \multicolumn{5}{|l|}{ HCV group } \\
\hline$-\quad<400,000 / \mathrm{ml}$ & $85(62.5$ & $12(44.4)$ & 0.081 & $2.08(0.90-4.80)$ \\
\hline$-\quad \geq 400,000 / \mathrm{ml}$ & $51(37.5)$ & $15(55.6)$ & & \\
\hline \multicolumn{5}{|l|}{ HCV group } \\
\hline$-\quad<600,000 / \mathrm{ml}$ & $89(65.4)$ & $17(63.0)$ & 0.805 & $1.11(0.47-2.63)$ \\
\hline$-\quad \geq 600,000 / \mathrm{ml}$ & 47 (34.6) & $10(37.0)$ & & \\
\hline \multicolumn{5}{|l|}{ Grade* } \\
\hline $\begin{array}{ll}- & 0.2\end{array}$ & $79(58.1)$ & $16(59.3)$ & 0.910 & $0.95(0.41-2.21)$ \\
\hline $3-4$ & $57(41.9)$ & $11(40.7)$ & & \\
\hline \multicolumn{5}{|l|}{ Stage* } \\
\hline 0.2 & $77(56.5)$ & $11(40.7)$ & 0.131 & $1.90(0.82-4.39)$ \\
\hline $\begin{array}{l}-\quad 3-4 \\
\end{array}$ & $59(43.5)$ & $16(59.3)$ & & \\
\hline \multicolumn{5}{|l|}{ Response to therapy } \\
\hline - SVR & $60(44.1)$ & $25(92.6)$ & 0.000 & $15.83(3.60-69.52)$ \\
\hline - No-SVR & $76(55.9)$ & $2(7.4)$ & & \\
\hline
\end{tabular}

Data expressed as mean $\pm S D$ or $n(\%)$ as appropriate. $n$; number. HCV; hepatitis $C$ virus. BMI; body mass index. SVR; sustained viral response. Grade (of inflammation) and stage (of fibrosis) by METAVIR score. OR; Odds ratio; CI; Confidence Interval. ALT; alanine transaminase. AST; Aspartate transaminase. ALP; alkaline phosphatase.

Table (3): Multivariate regression analysis of variables independently affecting SVR in patients with chronic HCV genotype 4 infection $(n=163)$

\begin{tabular}{lcccc}
\hline \multirow{2}{*}{ Variable } & \multirow{2}{*}{ Odds Ratio } & \multirow{2}{*}{ P Value } & \multicolumn{2}{c}{ 95\% Confidence Interval } \\
\cline { 4 - 5 } & & & Lower & Upper \\
\hline Albumin & 0.45 & 0.123 & 0.16 & 1.24 \\
IL28B "CC"* allele & 0.07 & 0.000 & 0.02 & 0.29 \\
\hline
\end{tabular}

n; number. *; Interferon-ג rs12979860 genotype CC. SVR; sustained virological response.

$H C V$; hepatitis $C$ virus. 

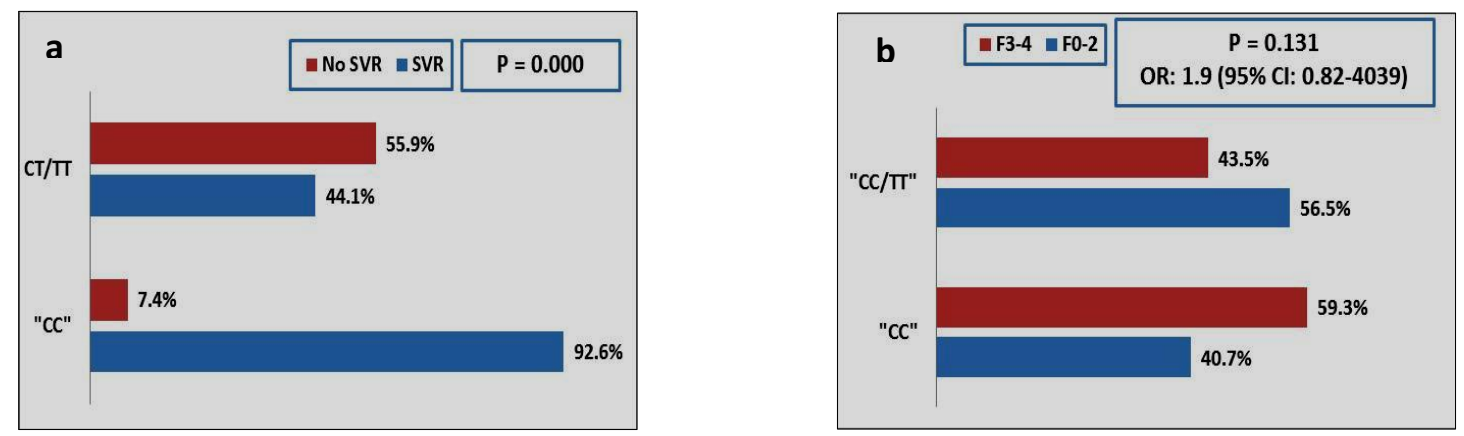

Figure (1) The percentage distribution of rs 12979860 in patients with SVR versus No-SVR (A), and patients with severe fibrosis $(\mathrm{F} \geq 3$ ) versus those with $\mathrm{F} 0-3$ (B); sustained virological response. "CC", "CT" and "TT" are rs12979860 alleles (genotypes). Test was done by Chi-Square and the Fisher's Exact tests.

\subsection{Severe hepatic fibrosis}

Compared to patients with nonsevere fibrosis stage (F0-2), patients with severe fibrosis (F3-4) were older $(\mathrm{P}=$ 0.002), had higher BMI $(\mathrm{P}=0.016)$, higher serum ALT $(\mathrm{P}=0.000)$, higher serum AST $(\mathrm{P}=0.000)$, lower serum albumin $(\mathrm{P}=$ 0.016), higher serum alkaline phosphatase $(\mathrm{P}=0.000)$, and more severe hepatic inflammation $(\mathrm{P}=0.000)$. The similar percentages $(P=0.552)$ of SVR and noSVR in patients with severe fibrosis (F3-4) and those without (F0-2) are shown in Figure 2. Confirming the importance of inflammation grade in predicting severe hepatic fibrosis (F3-4), severe inflammation (A3-4) was detected in $9.1 \%$ and $80 \%$ of patients with F0-2 and those with F3-4, multivariate logistic regression analysis, the independent predictors of severe fibrosis (F3-4) were age, serum AST, serum albumin, and inflammation grade, table (4).

\subsection{Sustained virological response (SVR)}

Compared to non-responders, patients who achieved SVR were similar regarding demographic, biochemical, virological, and pathological parameters. A total of $25 / 85(29.4 \%)$ of patients who achieved SVR and only $2 / 78(2.6 \%)$ of those who did not had the "CC" allele of the rs129798660 gene $(\mathrm{P}=0.001)$. Using multivariate logistic regression analysis, the independent predictors of SVR was only the $\mathrm{CC}$ allele of the rs12979860 gene $(\mathrm{P}=$ 0.000; OR: 0.07; CI: 0.02-0.29, table (3). respectively $(\mathrm{P}=0.000$; Figure 3$)$. Using

Table (4) Independent predictors of severe fibrosis_(F3-4) by multivariate regression analysis in patients with chronic HCV genotype 4 infection $(n=163)$.

\begin{tabular}{lcccc}
\hline \multirow{2}{*}{ Variable } & \multirow{2}{*}{ Odds Ratio } & \multirow{2}{*}{ P Value } & \multicolumn{2}{c}{ 95 \% Confidence Interval } \\
\cline { 4 - 5 } & & & Lower & Upper \\
\hline Age & 1.22 & $\mathbf{0 . 0 0 0}$ & 1.10 & 1.37 \\
BMI & 1.15 & 0.078 & 0.98 & 1.35 \\
ALT & 0.99 & 0.766 & 0.96 & 1.03 \\
AST & 1.05 & $\mathbf{0 . 0 3 3}$ & 1.00 & 1.10 \\
Albumin & 0.01 & $\mathbf{0 . 0 1 0}$ & 0.00 & 0.35 \\
ALP & 0.99 & 0.582 & 0.95 & 1.03 \\
Grade 3-4 & 0.01 & $\mathbf{0 . 0 0 0}$ & 0.00 & 0.04 \\
\hline
\end{tabular}

n; number. HCV; hepatitis C virus. BMI; body mass index. ALT; alanine transaminase. 


\section{Discussion}

In the last few years, polymorphism in the IL28B gene has been extensively investigated mainly in $\mathrm{HCV}$ genotype 1 infected patients because of its predictive role in HCV treatment outcome and possible association with disease progression [23]. It has been shown that allele distributions of IL28B SNPs are different between races and ethnic backgrounds [24].This partially explains the variations in response rates to antiviral therapy between different races and among different HCV genotypes. This study was conducted in a single center, with patients infected only with HCV genotype 4and absence of alcohol intake as a confounder, and with simultaneous testing of the role of the "CC" allele of the rs129798660 gene on both fibrosis and response to anti-viral therapy. These patients criteria makes this study different from previous studies that addressed the role of this gene polymorphism in predicting hepatic fibrosis because other studies included different genotypes, smaller number of $\mathrm{HCV}$ genotype 4 patients, patients with concomitant alcohol intake, and patients from different localities and ethnicities. The association of rs12979860 'CC' genotype with greater necro-inflammatory grade has been confirmed by many studies [12-14]. This is not the case with hepatic fibrosis stage and progression, where many controversial reports are published. ${ }^{12-21}$ In addition, a recent study by Noureddin et al, 2013 in (CHC-G1) patients added to such controversy [13].They showed that patients with the 'CC' genotype of rs12979860 had lower mean Ishak fibrosis scores, worse clinical outcomes, and greater hepatic inflammation compared to patients with other rs12979860 genotypes (CT/TT), together with no association between the rs12979860CC genotype with fibrosis progression on paired biopsies [13]. These findings are difficult to reconcile because hepatic fibrosis is a consequence of inflammation [1,25]. Also, inflammation grade on initial liver biopsy is the best predictor of fibrosis progression [26,27]. A recent meta-analysis of 28 studies that included 10,024 patients failed to resolve this controversy [28], probably reflecting the inter-study variability in the outcomes. In agreement with our results, a large study published recently by Eslam and colleagues was conducted in 4,172 patients;3, 129 of them with $\mathrm{CHC}$. They found that $\mathrm{CHC}$ patients with rs12979860CC had greater stage-constant and stage-specific fibrosis progression rates [29].This study utilized both cross-sectional and longitudinal studies and used a detailed validation strategy with multiple analytical approaches in a large cohort of patients. They confirmed that rs12979860 genotype is unequivocally associated with inflammation, fibrosis stage, and faster fibrosis progression. Indeed, this confirms the previous data that both viral- and hostrelated factors modulate hepatic fibrosis risk, and now provides additional strong evidence for an independent role for the rs12979860 polymorphism in modulating the phenotype and response to therapy. Consistent with the notion from other cohorts with dual liver biopsies $[25,26]$ that inflammation grade is a dominant driver of fibrosis, our study showed that patients with severe fibrosis have significantly 
higher inflammation grade in addition to elevated aminotransferases and alkaline phosphatase levels compared to those with less severe fibrosis. The present study confirms the association of the "CC" allele of the rs12979860 gene with more severe hepatic fibrosis. Moreover, the same allele is not only a predictor of $\mathrm{HCV}$ clearance and consequently a better response to antiviral therapy, as shown in other studies on patients infected with HCV genotype 4 [3033], but also it was found that this all ell is the only independent predictor of SVR in the included group. In addition, this study confirms the role of hepatic necroinflammatory grade as a predictor of more severe hepatic fibrosis. The mechanisms underlying the fibrogenic effect of rs12979860 genotypes are unclear. However, a recent study demonstrated that rs12979860 genotype up regulates cell death-related and survival-related networks in human infected and non-infected hepatocytes in responder patients [34]. Another study by Raglowet, et al. [35] showed a higher level of ISGs in non-infected livers of rs12979860 responder patients. Therefore, it is possible that rs12979860 genotype can render hepatocytes more efficient at responding to therapy, but on the other hand, may lead to more hepatocyte necro-inflammation and subsequent liver fibrosis [29]. So the confirmation from our results represented a milestone for decision to treat with IFNbased regimens, yet its role in predicting response to the directly acting antivirals needs further investigation. The important message is that once a patient's genotype is rs12979860 "CC", treatment needs to be given as soon as possible to benefit from good response to therapy, otherwise more fibrosis progression will be the consequence.

\section{Conclusion}

In conclusion, the present study that involved only CHC-G4 patients confirms that, contrary to patients with genotype 1, the 'CC' allele of rs 12979860 is associated with hepatic fibrosis progression, but better response to therapy necessitates early screening of CHC patients and early treatment of those with the ' $\mathrm{CC}$ ' allele to gain the benefit of the greater response to therapy before the progression of hepatic fibrosis.

\section{References}

[1] http://www.who.int/mediacentre/ fact sheets/ fs 164. 2012/en/ (Last seen in 5 Dec. 2015).

[2] Wantuck, J., Ahmed, A., Nguyen, M., (2014). The epidemiology and therapy of chronic hepatitis $C$ genotypes 4,5 and 6.: Review article. Aliment Pharmacol Ther.;39: 137-147.

[3] El-Zanaty, F. and Way, A., (2009). Egypt demographic and health survey 2008. Cairo, Egypt: Ministry of Health, El-Zanaty and Associates, and Macro International.

[4] Romero-Gomez, M., Eslam, M., Ruiz, A., Maraver, M., (2011). Genes and hepatitis C: susceptibility, fibrosis progression and response to treatment. Liver Int.; 31: 443-460.

[5] Patel, K., Norris, S., Lebeck, L., Feng, A., Clare, M., Pianko, S., et al., (2006). HLA class I allelic diversity and progression of fibrosis in patients with chronic hepatitis C. Hepatology; 43: 241-249. 
[6] Knapp, S., Yee, L., Frodsham, A., Hennig, B., Hellier, S., Zhang, L., et al., (2003). Polymorphisms in interferoninduced genes and the outcome of hepatitis $\mathrm{C}$ virus infection: roles of MxA, OAS-1 and PKR. Genes Immun.; 4: 411-419.

[7] Ge, D., Fellay, J., Thompson, A., Simon, J., Shianna, K., Urban, T., et al., (2009). Genetic variation in IL28B predicts hepatitis $\mathrm{C}$ treatment-induced viral clearance. Nature; 461: 399-401.

[8] Suppiah, V., Moldovan, M., Ahlenstiel, G., Berg, T., Weltman, M., Abate, M., et al., (2009). IL28B is associated with response to chronic hepatitis $\mathrm{C}$ interferon-alpha and ribavirin therapy. Nat Genet.; 41: 1100-1104.

[9] Tanaka, Y., Nishida, N., Sugiyama, M., Kurosaki, M., Matsuura, K., Sakamoto, N., et al., (2009). Genome-wide association of IL28B with response to pegylated interferon-alpha and ribavirin therapy for chronic hepatitis C. Nat Genet.; 41: 1105-1109.

[10] Eslam, M., Leung, R., RomeroGomez, M., Mangia, A., Irving, W., Sheridan, D., et al., (2014). IFNL3 polymorphisms predict response to therapy in chronic hepatitis $\mathrm{C}$ genotype 2/3 infection. J Hepatol; 61: 235-241.

[11] Prokunina-Olsson, L., Muchmore, B., Tang, W., Pfeiffer, R., Park, H., Dickensheets, H., et al., (2013). A variant upstream of IFNL3 (IL28B) creating a new interferon gene IFNL4 is associated with impaired clearance of hepatitis C virus. Nat Genet.; 45: 164-171.

[12] Bochud, P., Bibert, S., Kutalik, Z., Patin, E., Guergnon, J., Nalpas, B., et al., (2012). IL28B alleles associated with poor hepatitis $\mathrm{C}$ virus (HCV) clearance protect against inflammation and fibrosis in patients infected withnon-1 HCV genotypes. Hepatology; 55: 384-394.

[13] Noureddin, M., Wright, E., Alter, H., Clark, S., Thomas, E., Chen, R., et al., (2013). Association of IL28B genotype with fibrosis progression and clinical outcomes in patients with chronic hepatitis C: A longitudinal analysis. Hepatology; 58: 1548-1557.

[14] Thompson, A., Clark, J., Mingfu, Z., Qianqian, Z., Dongliang, G., Sulkowski, S., et al., (2010). Genome wideassociation study identifies IL28B polymorphism to be associated with baseline ALT and hepatic necro inflammatory activity in chronic hepatitis $\mathrm{C}$ patients enrolled in the IDEAL study (Abstract). Hepatology; 52: 1220A.

[15] Marabita, F., Aghemo, A., De Nicola, S., Rumi, M., Cheroni, C., Scavelli, R., et al., (2011). Genetic variation in the interleukin-28B gene is not associated with fibrosis progression in patients with chronic hepatitis $\mathrm{C}$ and known date of infection. Hepatology; 54: 1127-1134.

[16] Di Marco, V., Bronte, F., Calvaruso, V., Capra, M., Borsellino, Z., Maggio, A., et al., (2012). IL28B polymorphisms influence stage of fibrosis and spontaneous or interferon-induced viral clearance in thalassemia patients with hepatitis C virus infection.

Haematologica; 97: 679-686.

[17] Fabris, C., Falleti, E., Cussigh, A., Bitetto, D., Fontanini, E., Bignulin, S., 
et al., (2011). IL-28B rs12979860 C/T

allele distribution in patients with liver cirrhosis: role in the course of chronic viral hepatitis and the development of HCC. J Hepatol; 54: 716-722.

[18] Falleti, E., Bitetto, D., Fabris, C., Cussigh, A., Fornasiere, E., Cmet, S., et al., (2011). Role of interleukin 28B rs12979860 C/T polymorphism on the histological outcome of chronic hepatitis $\mathrm{C}$ : relationship with gender and viral genotype. J Clin Immunol; 31: 891-899.

[19] Abe, H., Ochi, H., Maekawa, T., Hayes, C., Tsuge, M., Miki, D., et al., (2010). Common variation of IL28 affects gamma-GTP levels and inflammation of the liver in chronically infected hepatitis $\mathrm{C}$ virus patients. $\boldsymbol{J}$ Hepatol; 53: 439-443.

[20] Garrett, M., Abdelmalek, M., AshleyKoch, A., Hauser, M., Moylan, C., Pang, H., et al., (2013). IL28B rs12979860 is not associated with histologic features of NAFLD in a cohort of Caucasian North American patients. J Hepatol; 58: 402-403.

[21] Petta, S., Grimaudo, S., Cammà, C., et al., (2012). IL28B and PNPLA3 polymorphisms affect histological liver damage in patients with non-alcoholic fatty liver disease. J Hepatol; 56: 1356-1362.

[22] Bedossa, P., Poynard, T., (1996). An algorithm for the grading of activity in chronic hepatitis C. The METAVIR Cooperative Study Group. Hepatology; 24: 289-293.

[23] Lange, C., Zeuzem, S., (2011). IL28B single nucleotide polymorphisms in the treatment of hepatitis C. J. Hepatol; 55: 692-701.
[24] Clark, P., Thompson, A., McHutchison, J., (2011). IL28B genomic-based treatment paradigms for patients with chronic hepatitis $\mathrm{C}$ infection: the future of personalized HCV therapies. Am $\boldsymbol{J}$ Gastroenterol.; 106: 38-45.

[25] Poynard, T., Ratziu, V., Charlotte, F., Goodman, Z., McHutchison, J., Albrecht, J., (2001). Rates and risk factors of liver fibrosis progression in patients with chronic hepatitis C. $J$ Hepatol; 34: 730-739.

[26] Ghany, M., Kleiner, D., Alter, H., Doo, E., Khokar, F., Promrat, K., et al., (2003). Progression of fibrosis in chronic hepatitis C. Gastroenterology; 124: 97-104.

[27] Ryder, S., Irving, W., Jones, D., Neal, K., Underwood, J., (2004). Progression of hepatic fibrosis in patients with hepatitis $\mathrm{C}$ : a prospective repeat liver biopsy study. Gut.; 53: 451-455.

[28] Sato, M., Kondo, M., Tateishi, R., Fujiwara, N., Kato, N., Yoshida, H., et al., (2014). Impact of IL28B genetic variation on $\mathrm{HCV}$-induced liver fibrosis, inflammation, and steatosis: a metaanalysis. PLoS One; 17: 9: e91822.

[29] Eslam, M., Hashem, A., Leung, R., Romero-Gomez, M., Berg, T., Dore, G., et al., (2015). Interferon- $\lambda$ rs12979860 genotype and liver fibrosis in viral and non-viral chronic liver disease. Nat Commun; 6: 6422.

[30] Asselah, T., De Muynck, S., Broet, P., Masliah-Planchon, J., Blanluet, M., Bieche, I., et al., (2012). IL28B polymorphism is associated with treatment response in patients with genotype 4 chronic hepatitis C. J Hepatol; 56: 527-532. 
[31] Scherzer, T., Stattermayer, A., Strasser, M., Laferl, H., Maieron, A., Stauber, R., et al., (2011). Impact of IL28B on treatment outcome in hepatitis $\mathrm{C}$ virus G1 / 4 patients receiving responseguided therapy with peginterferon alpha-2a (40KD) / ribavirin. Hepatology; 54: 1518-1526.
[32] De Nicola, S., Aghemo, A., Rumi, M., Galmozzi, E., Valenti, L., Soffredini, R., et al., (2012). Interleukin 28B polymorphism predicts pegylated interferon plus ribavirin treatment outcome in chronic hepatitis $\mathrm{C}$ genotype 4. Hepatology; 55: 336-342. 
